\title{
Preoperative lymphocyte-to-monocyte ratio in the prognostication of advanced resectable colon cancer: A retrospective observational study
}

\section{Kenta Kasahara ( $\sim$ kasadog@tokyo-med.ac.jp )}

Tokyo Medical University: Tokyo lka Daigaku https://orcid.org/0000-0001-5997-5919

\section{Tetsuo Ishizaki}

Tokyo Medical University: Tokyo Ika Daigaku

\section{Masanobu Enomoto}

Tokyo Medical University: Tokyo Ika Daigaku

Junichi Mazaki

Tokyo Medical University: Tokyo Ika Daigaku

\section{Naoto Okazaki}

Tokyo Medical University: Tokyo Ika Daigaku

\section{Tomoya Tago}

Tokyo Medical University: Tokyo Ika Daigaku

\section{Ryutaro Udo}

Tokyo Medical University: Tokyo Ika Daigaku

\section{Yuichi Nagakawa}

Tokyo Medical University: Tokyo Ika Daigaku

Kenji Katsumata

Tokyo Medical University: Tokyo Ika Daigaku

Akihiko Tsuchida

Tokyo Medical University: Tokyo Ika Daigaku

\section{Research article}

Keywords: lymphocyte-to-monocyte ratio, resectable advanced Colon Cancer, TNM staging, Prognosis prediction

Posted Date: October 9th, 2020

DOI: https://doi.org/10.21203/rs.3.rs-87462/v1

License: (c) (1) This work is licensed under a Creative Commons Attribution 4.0 International License. 
Version of Record: A version of this preprint was published at Indian Journal of Surgical Oncology on July 8th, 2021. See the published version at https://doi.org/10.1007/s13193-021-01356-y. 
Title: Preoperative lymphocyte-to-monocyte ratio in the prognostication of advanced resectable colon cancer: A retrospective observational study

Kenta Kasahara $^{1}$, MD; Tetsuo Ishizaki ${ }^{1}, \mathrm{PhD}$; Masanobu Enomoto ${ }^{1}, \mathrm{PhD}$; Junichi Mazaki ${ }^{1}$, MD; Naoto

Okazaki $^{1}$, MD; Tomoya Tago ${ }^{1}$, MD; Ryutaro Udo ${ }^{1}$, MD; Yuichi Nagakawa ${ }^{1}, \mathrm{PhD}$; Kenji Katsumata ${ }^{1}$, PhD; Akihiko Tsuchida ${ }^{1}, \mathrm{PhD}$

${ }^{1}$ Department of Gastrointestinal and Pediatric Surgery, Tokyo Medical University, 6-7-1 Nishi Shinjuku,

Shinjuku-ku, Tokyo 160-0023, Japan

Corresponding Author: Kenta Kasahara

Tokyo Medical University, 6-7-1 Nishi Shinjuku, Shinjuku-ku, Tokyo 160-0023, Japan

Email: kasadog@tokyo-med.ac.jp

Phone: +81-3-3342-6111 


\section{Abstract}

Background: Lymphocyte-to-monocyte ratio (LMR) has been reported as a biomarker for predicting the prognosis of colorectal cancer. However, proof of the clinical usefulness of LMR requires detailed research on subjects that can contribute to therapeutic strategies. Our study aimed to provide a detailed link to resectable advanced colorectal cancer for which LMR is predicted to be particularly useful.

Methods: A cohort of 554 resectable advanced colon cancer patients in our institution was analysed retrospectively. The analysis was performed on all cases of resectable advanced colon cancer and Stage II and Stage III. Receiver operating characteristic curve analyses were performed to determine the LMR cutoff value. The relationship between LMR, clinicopathologic factors, and other biomarkers were analysed using a Kaplan-Meier log-rank survival analysis and then multivariate Cox regression models looking for association with overall survival (OS) and Relapse free survival (RFS).

Results: LMR was useful for predicting OS and RFS in the analysis of all cases. Moreover, it was an independent prognostic factor in the multivariate analysis [hazard ratio $(\mathrm{HR})=0.530,95 \%$ confidence intervals $(\mathrm{CI})=0.334-0.842, \mathrm{P}=0.007]$. LMR was also an independent prognostic predictor at each stage. In particular, it was highly useful for prediction in cases with lymph node metastasis (StageIII) and was a prognostic predictor following the $\mathrm{N}$ factor. 
Conclusion: LMR is useful in the prognosis of resectable advanced colon cancer. In addition, it may be characterised by having a high effect on the prognosis of patients with lymph node metastasis. This study may influence postoperative strategies for colon cancer, such as the study of Stage III chemotherapy indications, and is expected to facilitate further detailed studies.

Keywords: lymphocyte-to-monocyte ratio, resectable advanced Colon Cancer, TNM staging, Prognosis prediction 


\section{Background}

Colorectal cancer (CRC) is among the leading causes of cancer-related deaths worldwide, and it is associated with 1.4 million diagnosed and nearly 700,000 deaths per year [1]. CRC prognosis is based on the Union for International Cancer Control (UICC) tumour node metastasis (TNM) classification; however, differences in outcomes have been reported among patients presenting with the same disease stage [2]. Concurrently, various inflammatory biomarkers have been suggested as relevant survival predictors in this patient group [3, 4]. For example, the lymphocyte-to-monocyte ratio (LMR) is a recently proposed biomarker that reflects the immune system function and may help predict outcomes in patients with CRC

[5]. However, previous studies that examined this association in CRC involved heterogeneous samples, including those of patients with varied disease location and stage, and few previous reports differentiated patients based on their clinical characteristics. CRC prognosis depends on disease stage and location, e.g., colon vs rectum and right vs left side $[6,7]$. As a result, the relevance of LRM in CRC remains to be examined for each disease subgroup. This study aimed to examine the role of preoperative LMR in the prognostication of advanced resectable colon cancer (CC). 


\section{Methods}

We retrospectively examined the data of 554 consecutive patients with advanced resectable $\mathrm{CC}$ who underwent radical surgery at the Tokyo Medical University Hospital between January 2000 and March 2015. All patients were eligible for this study regardless of the timing of surgery or method used. Patients were excluded from this study if they had preoperative blood count deficiencies (including white or red blood cell count, platelet count, or white blood cell fraction), rectal cancer, or an unresectable tumour. The CC stage was classified according to the eighth edition of the American Joint committee on Cancer/Union for International Cancer Control (AJCC/UICC) TNM classification system. Background factors, such as "age", “sex", "BMI", “T", "N", "ly", “v", "timing of surgery", "tumour location", and "tumour size", were compared with separated groups. In survival analysis, the neutrophil-lymphocyte ratio (NLR) and plateletlymphocyte ratio (PLR) that can be calculated by blood count and are used to compare other biomarkers that can predict prognosis in colorectal cancer.

Statistical analysis

Receiver operating characteristic (ROC) curve analysis was used to determine the appropriate cut-off value for predicting the prognosis of LMR. ROC analyses were performed using EZR. Based on this cut-off 
value, patients were classified into the "high" (H group) and "low" (L group) LMR groups. Patient baseline characteristics in each LMR group were compared using the $\chi^{2}$ and Fisher's exact test. The association of LMR with overall survival (OS) and recurrence-free survival (RFS) was analysed using the Kaplan-Meier method and log-rank test. Multivariate Cox regression analyses were also performed. All statistical analyses were performed with the Statistical Package for Social Science (SPSS) software package (SPSS Inc., Tokyo, Japan). P-values $<0.05$ were considered to indicate statistical significance.

\section{Ethics statement}

This study adhered to the Declaration of Helsinki and was approved by the ethics committee of Tokyo Medical University Hospital (T2019-0054). This study was approved by the institutional ethics board, and informed consent was obtained from the patients.

\section{Results}

Patient characteristics are presented in Table 1. The study sample included 342 men (62.7\%) and 212 women $(37.1 \%)$. The median age of the patients was 69.0 (range, 30-94) years. In addition, $49(8.8 \%)$ 
patients underwent emergency tumour resection owing to perforation or obstruction. Morphology findings in all patients were based on tests performed closest to the date of surgery. LMR was calculated as the ratio of the number of lymphocytes to that of monocytes in the complete blood count test. All pathological decisions were made by a gastrointestinal pathology specialist from the Department of Clinical Pathology of the same hospital. At our institution, postoperative adjuvant chemotherapy (ADJ) is mainly administered to patients with Stage III disease; however, $13 \%$ of patients with Stage III disease in the present study did not receive ADJ.

LMR cut-off value

The median LMR during preoperative examination was 4.067 (range, 0.180-216.5). The median observation period for all patients was 2113 (range, 3-7081) days. The ROC curve revealed an LMR value of 2.77 as a cut-off for OS. Patients showing LMR higher than the set cut-off value were assigned into the $\mathrm{H}$ group, and those showing LMR lower than the set cut-off value were assigned into the L group. There were 426 and 128 patients in the $\mathrm{H}$ and $\mathrm{L}$ groups, respectively.

LMR and patient characteristics

The characteristics of patients in the $\mathrm{H}$ and $\mathrm{L}$ groups are presented in Table 2. Univariate analysis revealed 
differences in tumour location between the $\mathrm{H}$ and $\mathrm{L}$ groups; there were more cases of left-sided $\mathrm{CC}$ in the $\mathrm{H}$ group than in the L group. In addition, patients in the $\mathrm{H}$ group tended to be younger, although there was no statistically significant difference in age between the groups.

Survival analysis for the whole sample

The Kaplan-Meier method revealed that OS and RFS rates were significantly better in the H group than in the L group ( $\mathrm{p}=0.002$, Fig $1-\mathrm{a} ; \mathrm{p}=0.03$, Fig. 1-b, respectively). Univariate analyses were performed on LMR, NLR, PLR, and other clinicopathologic factors to determine their association with OS; those that were significant were evaluated in the multivariate analysis. In the multivariate analysis, age, $\mathrm{N}, \mathrm{v}$, timing of surgery, and LMR were independent prognostic factors (Table3). A High LMR was associated with a high hazard ratio $(\mathrm{HR})(\mathrm{HR}=0.530,95 \%$ confidence interval $[\mathrm{CI}]=0.334-0.842, \mathrm{P}=0.007)$. This was useful for prognostication after the results of factor $\mathrm{N}(\mathrm{HR}=0.424,95 \%$ confidence interval $[\mathrm{CI}]=0.266-0.676$, $\mathrm{P}=0.007)$. 
The cut-off value of LMR in patients with Stage II disease for OS was 3.33. Patients with Stage II disease were categorised into LMR II-H (LMR > 3.33) and II-L (LMR $\leq 3.33)$ groups. There was no statistically significant difference between the groups regarding background characteristics. Although OS was favourable in the II-H group, there was no statistically significant difference between the groups $(\mathrm{p}=0.104$, Fig 2-a). Meanwhile, RFS was favourable in the II-H group ( $p=0.03$, Fig 2-b).

Univariate analysis was performed on age, gender, LMR, NLR, PLR, and other clinicopathological factors to determine their association with RFS. Factor N was excluded because it was negative in all cases. The significant factors were evaluated in the multivariate analysis. In the multivariate analysis, v and LMR were independent prognostic factors (Table 4).

The cut-off value of LMR for OS in patients with Stage III disease was 2.68. Patients with Stage III disease were categorised into LMR III-H $(\mathrm{LMR}>2.68)$ and III-L $(\mathrm{LMR} \leq 2.68)$ groups. There was no statistically significant difference between the groups regarding background characteristics. However, OS was significantly better in the III-H group than in the III-L group ( $p<0.001$, Fig 3 -a), as was RFS ( $p=0.002$, Fig $3-b)$.

Univariate analysis was performed on age, gender, LMR, NLR, PLR, and other clinicopathological factors to determine their association with RFS. Since all cases had lymph node metastasis, the number of $\mathrm{N}$ was 
newly added as a factor. Nwas stratified as follows: a group with less than 3 lymph node metastases corresponding to N1 according to the TNM classification and a group with more than 4 lymph node metastases corresponding to N2/N3 according to the TNM classification. Significant factors were evaluated in the multivariate analysis. In the multivariate analysis, the number of $\mathrm{N}$ and LMR were independent prognostic factors (Table 5). LMR was the predictor most strongly associated with prognosis in patients with Stage III disease.

\section{Discussion}

Several biomarkers for CRC outcomes have been proposed [8]. Joseph et al. hypothesised that LMR reflects tumour growth and that it may be useful as a prognostic factor for T-factor, left-size, and colon-located tumour [5]. CRC location is associated with specific genetic characteristics and optimum treatment strategies, e.g., colon vs rectum and right vs left side [1,21, 22]. Based on these findings, LMR has been proposed as a potential prognostic factor in advanced resectable $\mathrm{CC}$; however, its relationship with $\mathrm{N}$ factors remains unclear.

As a prognostic factor in CTC, LMR has been suggested as superior to the TNM stage classification of disease. The contribution of prognostic factors such as LMR to treatment strategy selection should be 
considered for each disease stage. In Stage II-IIII CRC, postoperative clinical characteristics tend to affect subsequent treatment selection; however, conclusive stratification remains to be achieved. Disease characteristics considered in the present study were selected based on the Japanese Society for Cancer of Colon and Rectum and the National Comprehensive Cancer Network guidelines [21, 22].

Previously proposed LMR cut-off values range from 2.14 to 4.19 [5, 11-20]. The LMR score in this study ranged from 2.67 to 3.33 , which is within the previously reported range. NLR and PLR have been previously suggested as prognostic markers for CRC; their effect was compared with that of LMR. The previously reported cut-off values of PLR and NLR were $150-300$ and $2-5$, respectively. The cut-off value of each factor of interest in this study was adopted from the study by Tokunaga et al. [23].

The present study supported the use of LMR as a prognostic factor in patients with advanced resectable CC.

Besides lymph node metastasis, LMR was the only significant prognostic factor in the overall analysis in the present study, suggesting its superiority over other proposed biomarkers and pathological factors. These findings are consistent with those of previous studies in CRC; this is the first study to consider CC patients alone $[5,9,18,24]$.

In the analysis of patients with Stage II disease, there was a statistically significant between-group difference in RFS but not OS. In previous reports, LMR was associated with OS in stage II CRC patients 
[5]. Although the present study involved a similar sample size, it only included patients with CC. Overall, $\mathrm{CC}$ is associated with a better prognosis than CRC, and it was considered that the fewer Stage II CC events recorded in this analysis were because of a more limited number of events in CRC studies. In the present study, except for the $\mathrm{v}$ factor, LMR had a bigger effect on RFS than did other clinicopathologic features, suggesting LMR could be used to inform postoperative treatment strategies.

LMR appeared to have a bigger effect on prognosis in patients with Stage II disease than in those with Stage III disease. Few reports have examined the effect of LMR on the prognosis of Stage III CRC. For example, Stotz et al. questioned the usefulness of adj for patients with characteristics such as those of the III-L group. However, its usefulness in clinical practise remains uncertain as it has not been validated against other clinicopathological factors. This study entailed a comparison of LMR utility with that of other clinicopathological factors, suggesting that LMR might be a useful factor in the prognostication of Stage III CC. In particular, compared to the number of metastases or lymph node metastases corresponding to the $\mathrm{N} 1$ and $\mathrm{N} 2$ categories in the TNM classification, LMR allowed independent and more accurate stratification. This finding is consistent with LMR characteristics; as a growth factor, its association with disease prognosis is biologically different from that of lymph node metastasis. This finding might help inform new treatment strategies for Stage III CC, which have been based on lymph node metastasis to date. 
This study had some limitations that should be considered when interpreting the findings. First, this was a retrospective observational study based on data from patients treated at a single institution. Second, it was difficult to categorise cases of Stage III disease receiving ADJ. The standard ADJ has changed over time; in addition, treatment decisions were at the discretion of attending physicians. Previously, Cham et al. reported that NLR was not useful as a prognostic factor in patients with Stage III disease receiving ADJ; however, this limitation does not significantly affect the validity of the present findings [5]. Finally, some reports have suggested that LMR may help predict the effect of ADJ; this hypothesis should be examined in more detail [19].

\section{Conclusion}

LMR is useful in the prognosis of resectable advanced colon cancer. In addition, it may be characterised by having a high effect on the prognosis of patients with lymph node metastasis. This study may influence postoperative strategies for colon cancer, such as the study of Stage III chemotherapy indications, and it is expected to facilitate further detailed studies.

\section{List of abbreviations}


Colorectal cancer (CRC), Union for International Cancer Control (UICC), Tumour node metastasis (TNM), Lymphocyte-to-monocyte ratio (LMR), Colon cancer (CC), the American Joint committee on Cancer/Union for International Cancer Control (AJCC/UICC), neutrophil-lymphocyte ratio (NLR), platelet-lymphocyte ratio (PLR), Receiver operating characteristic (ROC), Adjuvant chemotherapy (ADJ), Overall survival (OS), Recurrence-free survival (RFS)

\section{Declarations}

\section{- Ethics approval and consent to participate:}

This study adhered to the Declaration of Helsinki and was approved by the ethics committee of Tokyo Medical University Hospital(T2019-0054). This study was approved by institutional ethics board, and informed consent was taken from the patient.

\section{- Consent for publication}

Not applicable

\section{- Availability of data and materials}

The datasets during and/or analysed during the current study available from the corresponding author 
on reasonable request.

\section{- Competing interests:}

The authors have no conflicts of interest directly relevant to the content of this article.

\section{- Funding:}

The authors have no conflicts of interest directly relevant to the content of this article.

\section{- Authors' contributions:}

Kenta Kasahara contributed to the concept and design of the study, collection and interpretation of data, writing of the manuscript, and revision of the manuscript for important content. Kenji

Katsumata contributed to the concept and design of the study, interpretation of data, and revision of the manuscript for important content. Tetsuo Ishizaki, Masanobu Enomoto, Junichi Masaki, Naoto Okazaki, Tomoya Tago, Yuichi Nagakawa, Akihiko Tsuchida contributed to the collection and interpretation of data and revision of the manuscript for important content. All authors have approved the final version of the manuscript.

\section{- Acknowledgements:}

Not applicable 


\section{- Authors' information}

Not applicable

\section{References}

1. McGuire S. World Cancer Report 2014. Geneva, Switzerland: World Health Organization, International Agency for Research on Cancer, WHO Press, 2015. Adv Nutr. 2016;7:418-9.

2. Hari DM, Leung AM, Lee JH, Sim MS, Vuong B, Chiu CG, Bilchik AJ. AJCC Cancer Staging Manual 7th edition criteria for colon cancer: do the complex modifications improve prognostic assessment? J Am Coll Surg. 2013;217:181-90.

3. McMillan DC. The systemic inflammation-based Glasgow Prognostic Score: a decade of experience in patients with cancer. Cancer Treat Rev. 2013;39:534-40.

4. Rossi S, Basso M, Strippoli A, Schinzari G, D'Argento E, Larocca M, et al. Are markers of systemic inflammation good prognostic indicators in colorectal cancer? Clin Colorectal Cancer. 2017;16:264-74.

5. Chan JC, Chan DL, Diakos CI, Engel A, Pavlakis N, Gill A, et al. The lymphocyte-to-monocyte 
ratio is a superior predictor of overall survival in comparison to established biomarkers of resectable colorectal cancer. Ann Surg. 2017;265:539-46.

6. Benedix F, Kube R, Meyer F, Schmidt U, Gastinger I, Lippert H Comparison of 17,641 patients with right- and left-sided colon cancer: differences in epidemiology, perioperative course, histology, and survival. Dis Colon Rectum. 2010;53:57-64.

7. Moritani K, Hasegawa H, Okabayashi K, Ishii Y, Endo T, Kitagawa Y. Difference in the recurrence rate between right- and left-sided colon cancer: a 17 -year experience at a single institution. Surg Today. 2014;44:1685-91.

8. Aoyama T, Oba K, Hamada C, Sadahiro S, Honda M, Mayanagi S, et al: Comparison of clinic pathological characters and survival between right- and left-side colon cancer. Annals of Cancer Research and Therapy 2016, 24(2):62-63.

9. Yang J, Xu H, Guo X, Zhang J, Ye X, Yang Y, et al. Pretreatment inflammatory indexes as prognostic predictors for survival in colorectal cancer patients receiving neoadjuvant chemoradiotherapy. Sci Rep. 2018;8:3044.

10. Nishijima TF, Muss HB, Shachar SS, Tamura K, Takamatsu Y. Prognostic value of lymphocyteto-monocyte ratio in patients with solid tumors: A systematic review and meta-analysis. Cancer 
Treat Rev. 2015;41:971-8.

11. Xu J, Li Y, Hu S, Lu L, Gao Z, Yuan H. The significant value of predicting prognosis in patients with colorectal cancer using 18F-FDG PET metabolic parameters of primary tumors and hematological parameters. Ann Nucl Med. 2019;33:32-8.

12. Kamonvarapitak T, Matsuda A, Matsumoto S, Jamjittrong S, Sakurazawa N, Kawano Y, et al. Preoperative lymphocyte-to-monocyte ratio predicts postoperative infectious complications after laparoscopic colorectal cancer surgery. Int J Clin Oncol. 2020;25:633-40.

13. Park JW, Chang HJ, Yeo HY, Han N, Kim BC, Kong SY, et al. The relationships between systemic cytokine profiles and inflammatory markers in colorectal cancer and the prognostic significance of these parameters. Br J Cancer. 2020;123:610-8.

14. Guo G, Wang Y, Zhou Y, Quan Q, Zhang Y, Wang H, et al. Immune cell concentrations among the primary tumour microenvironment in colorectal cancer patients predicted by clinicopathologic characteristics and blood indexes. J Immunother Cancer. 2019;7:179.

15. Li Y, Wu H, Xing C, Hu X, Zhang F, Peng Y, et al. Prognostic evaluation of colorectal cancer using three new comprehensive indexes related to infection, anemia and coagulation derived from peripheral blood. J Cancer. 2020;11:3834-45. 
16. Shibutani M, Maeda K, Nagahara H, Iseki Y, Ikeya T, Hirakawa K. Prognostic significance of the preoperative lymphocyte-to-monocyte ratio in patients with colorectal cancer. Oncol Lett. 2017; $13: 1000-6$

17. Li X, Guo D, Chu L, Huang Y, Zhang F, Li W, et al. Potential diagnostic value of combining inflammatory cell ratios with carcinoembryonic antigen for colorectal cancer. Cancer Manag Res. 2019;11:9631-40

18. Song Y, Yang Y, Gao P, Chen X, Yu D, Xu Y, et al. The preoperative neutrophil to lymphocyte ratio is a superior indicator of prognosis compared with other inflammatory biomarkers in resectable colorectal cancer. BMC Cancer. 2017;17:744.

19. Stotz M, Pichler M, Absenger G, Szkandera J, Arminger F, Schaberl-Moser R, et al. The preoperative lymphocyte to monocyte ratio predicts clinical outcome in patients with stage III colon cancer. Br J Cancer. 2014;110:425-40.

20. Ozawa T, Ishihara S, Kawai K, Kazama S, Yamaguchi H, Sunami E, et al. Impact of a lymphocyte to monocyte ratio in stage IV colorectal cancer. J Surg Res. 2015;199:386-92.

21. Benson AB, 3rd, Venook AP, Cederquist L, Chan E, Chen YJ, Cooper HS, et al. Colon Cancer, Version 1.2017, NCCN Clinical Practice Guidelines in Oncology. J Natl Compr Canc Netw. 
$2017 ; 15: 370-98$.

22. Hashiguchi Y, Muro K, Saito Y, Ito Y, Ajioka Y, Hamaguchi T, et al. Japanese Society for Cancer of the Colon and Rectum (JSCCR) guidelines 2019 for the treatment of colorectal cancer. Int J Clin Oncol. 2020;25:1-42.

23. Tokunaga R, Sakamoto Y, Nakagawa S, Izumi D, Kosumi K, Taki K, et al. Comparison of systemic inflammatory and nutritional scores in colorectal cancer patients who underwent potentially curative resection. Int J Clin Oncol. 2017;22:740-8.

24. Guo YH, Sun HF, Zhang YB, Liao ZJ, Zhao L, Cui J, et al. The clinical use of the platelet/lymphocyte ratio and lymphocyte/monocyte ratio as prognostic predictors in colorectal cancer: a meta-analysis. Oncotarget. 2017;8:20011-24.

Figure legends

Fig 1. Overall survival (A) and recurrence-free survival (B) among colorectal cancer patients according to the lymphocyte-to-monocyte ratio.

Survival curves were derived using the Kaplan-Meier method. $\mathrm{P}<0.05$ was considered to indicate statistical 
significance.

Fig 2. Overall survival (A) and recurrence-free survival (B) findings among colorectal cancer patients with Stage II disease according to the lymphocyte-to-monocyte ratio.

Survival curves were derived using the Kaplan-Meier method. $\mathrm{P}<0.05$ was considered to indicate statistical significance.

Fig 3. Overall survival (A) and recurrence-free survival (B) among colorectal cancer patients with Stage III disease according to the lymphocyte-to-monocyte ratio.

Survival curves were derived using the Kaplan-Meier method. $\mathrm{P}<0.05$ was considered to indicate statistical significance.

Tables

Table 1. Patient demographic and clinical characteristics 


\begin{tabular}{|c|c|}
\hline & $n(\%)$ \\
\hline \multicolumn{2}{|l|}{ Sex } \\
\hline male & $342(62.7)$ \\
\hline female & $212(37.1)$ \\
\hline \multicolumn{2}{|l|}{ Age (years) } \\
\hline$<75$ & $381(68.8)$ \\
\hline$\geq 75$ & $173(31.2)$ \\
\hline \multicolumn{2}{|l|}{ Body mass index $\left(\mathrm{kg} / \mathrm{m}^{2}\right)$} \\
\hline$\geq 25$ & $153(27.6)$ \\
\hline$<25$ & $401(72.4)$ \\
\hline \multicolumn{2}{|l|}{ Stage } \\
\hline ॥ & $280(50.5)$ \\
\hline III & $274(49.5)$ \\
\hline \multicolumn{2}{|l|}{ ly } \\
\hline Positive & $278(70.9)$ \\
\hline Negative & $114(29.1)$ \\
\hline \multicolumn{2}{|l|}{ v } \\
\hline Positive & $360(65.5)$ \\
\hline Negative & $189(34.5)$ \\
\hline \multicolumn{2}{|l|}{ Histology findings } \\
\hline Well/mod & 505 (91.2) \\
\hline Other & $49(8.8)$ \\
\hline \multicolumn{2}{|l|}{ T factor } \\
\hline $\mathrm{T} 1,2,3$ & 451 (81.4) \\
\hline $\mathrm{T} 4$ & 103 (18.6) \\
\hline \multicolumn{2}{|l|}{ Tumour location } \\
\hline right-side & $244(44.0)$ \\
\hline left-side & $310(56.0)$ \\
\hline \multicolumn{2}{|l|}{ Tumour size $(\mathrm{cm})$} \\
\hline$<5$ & $295(53.2)$ \\
\hline$\geq 5$ & $259(46.8)$ \\
\hline \multicolumn{2}{|l|}{ Emergency surgery } \\
\hline Yes & $49(8.8)$ \\
\hline No & 505 (91.2) \\
\hline \multicolumn{2}{|l|}{ Operation method } \\
\hline Laparoscopic & $183(33.0)$ \\
\hline Open & $371(67.0)$ \\
\hline
\end{tabular}

Table 2. Comparisons of patient characteristics according to the lymphocyte-to-monocyte ratio 


\begin{tabular}{|c|c|c|c|}
\hline & LMR-Iow & LMR-high & $p$-value \\
\hline & $(<2.77)$ & $(\geq 2.77)$ & \\
\hline Sex & & & 0.254 \\
\hline Male & 85 & 257 & \\
\hline Female & 43 & 169 & \\
\hline Age (years) & & & 0.051 \\
\hline$<75$ & 79 & 302 & \\
\hline$\geq 75$ & 49 & 124 & \\
\hline Body mass index $(\mathrm{kg} / \mathrm{m}$ & & & 0.663 \\
\hline$\geq 25$ & 33 & 120 & \\
\hline$<25$ & 95 & 306 & \\
\hline $\mathrm{N}$ & & & 0.107 \\
\hline Negative & 55 & 219 & \\
\hline Positive & 73 & 207 & \\
\hline ly & & & 0.808 \\
\hline Negative & 26 & 88 & \\
\hline Positive & 71 & 207 & \\
\hline v & & & 0.167 \\
\hline Negative & 37 & 152 & \\
\hline Positive & 90 & 270 & \\
\hline Histology findings & & & 0.594 \\
\hline Well/mod & 115 & 390 & \\
\hline Other & 13 & 36 & \\
\hline T factor & & & 0.3 \\
\hline $\mathrm{T} 1,2,3$ & 100 & 351 & \\
\hline $\mathrm{T} 4$ & 28 & 75 & \\
\hline Tumour location & & & 0.033 \\
\hline right-side & 67 & 177 & \\
\hline left-side & 61 & 249 & \\
\hline Tumour size & & & 0.13 \\
\hline$<5 \mathrm{~cm}$ & 76 & 219 & \\
\hline$\geq 5 \mathrm{~cm}$ & 52 & 207 & \\
\hline Emergency surgery & & & 0.214 \\
\hline No & 113 & 392 & \\
\hline Yes & 15 & 34 & \\
\hline Operation method & & & 0.915 \\
\hline Open & 86 & 285 & \\
\hline Laparoscopic & 41 & 140 & \\
\hline
\end{tabular}

Table 3. Results of long-term prognostic analysis based on LMR classification of all cases 


\begin{tabular}{|c|c|c|c|c|c|}
\hline \multirow[b]{2}{*}{ Variable } & \multirow[b]{2}{*}{$N(\%)$} & \multirow{2}{*}{$\begin{array}{c}\text { Univariate analysis } \\
P \text {-value }\end{array}$} & \multicolumn{3}{|c|}{ Multivariate analysis } \\
\hline & & & Hazard Ratio & $95 \% \mathrm{Cl}$ & $P$-value \\
\hline Sex & & 0.323 & & & \\
\hline Male & $342(62.7)$ & & & & \\
\hline Female & $212(37.1)$ & & & & \\
\hline Age (years) & & 0.001 & 2.010 & $1.287-3.138$ & 0.002 \\
\hline$<75$ & $381(68.8)$ & & & & \\
\hline$\geq 75$ & $173(31.2)$ & & & & \\
\hline \multicolumn{2}{|c|}{ Body mass index $\left(\mathrm{kg} / \mathrm{m}^{2}\right)$} & 0.869 & & & \\
\hline$\geq 25$ & $153(27.6)$ & & & & \\
\hline$<25$ & $401(72.4)$ & & & & \\
\hline $\mathrm{N}$ & & $<0.001$ & 0.424 & $0.266-0.676$ & $<0.001$ \\
\hline Negative & $274(49.5)$ & & & & \\
\hline Positive & $280(50.5)$ & & & & \\
\hline ly & & 0.073 & & & \\
\hline Negative & $114(29.1)$ & & & & \\
\hline Positive & $278(70.9)$ & & & & \\
\hline v & & 0.007 & 0.556 & $0.328-0.942$ & 0.029 \\
\hline Negative & $189(34.5)$ & & & & \\
\hline Positive & $360(65.5)$ & & & & \\
\hline \multicolumn{2}{|c|}{ Histology findings } & 0.042 & 0.593 & $0.301-1.171$ & 0.132 \\
\hline Well/mod & $505(91.2)$ & & & & \\
\hline Other & $49(8.8)$ & & & & \\
\hline $\mathrm{T}$ factor & & 0.003 & 1.501 & $0.923-2.441$ & 0.101 \\
\hline $\mathrm{T} 1,2,3$ & $451(81.4)$ & & & & \\
\hline $\mathrm{T} 4$ & $103(18.6)$ & & & & \\
\hline \multicolumn{2}{|l|}{ Tumour location } & 0.631 & & & \\
\hline Right-side & $244(44.0)$ & & & & \\
\hline Left-side & $310(56.0)$ & & & & \\
\hline \multicolumn{2}{|c|}{ Tumour size $(\mathrm{cm})$} & 0.101 & & & \\
\hline$<5$ & $295(53.2)$ & & & & \\
\hline$\geq 5$ & $259(46.8)$ & & & & \\
\hline \multicolumn{2}{|c|}{ Emergency surgery } & 0.033 & 0.475 & $0.252-0.894$ & 0.021 \\
\hline No & $505(91.2)$ & & & & \\
\hline Yes & $49(8.8)$ & & & & \\
\hline \multicolumn{2}{|c|}{ Operation method } & 0.904 & & & \\
\hline Open & $183(33.0)$ & & & & \\
\hline Laparoscopic & $371(67.0)$ & & & & \\
\hline LMR & & 0.002 & 0.530 & $0.334-0.842$ & 0.007 \\
\hline$\geq 2.77$ & $426(76.9)$ & & & & \\
\hline$<2.77$ & $128(23.1)$ & & & & \\
\hline PLR & & 0.242 & & & \\
\hline$\geq 300$ & 99 (17.9) & & & & \\
\hline$<300$ & $455(82.1)$ & & & & \\
\hline NLR & & 0.054 & & & \\
\hline$\geq 5.00$ & $82(14.8)$ & & & & \\
\hline$<5.00$ & $472(85.2)$ & & & & \\
\hline
\end{tabular}

This table shows the results of a comparison of long-term prognostic factors for all cases based on the LMR

classification. $\mathrm{P}<0.05$ was considered to be statistically significant 
Table4. Results of long-term prognostic analysis based on LMR classification in stage II cases

\begin{tabular}{|c|c|c|c|c|c|}
\hline \multirow[b]{2}{*}{ Variable } & \multirow[b]{2}{*}{$N(\%)$} & \multirow{2}{*}{$\begin{array}{c}\text { Univariate analysis } \\
P \text {-value }\end{array}$} & \multicolumn{3}{|c|}{ Multivariate analysis } \\
\hline & & & Hazard Ratio & $95 \% \mathrm{Cl}$ & $P$-value \\
\hline Sex & & 0.933 & & & \\
\hline Male & $187(66.8)$ & & & & \\
\hline Female & $93(33.2)$ & & & & \\
\hline Age (years) & & 0.662 & & & \\
\hline$<75$ & $190(67.9)$ & & & & \\
\hline$\geq 75$ & $90(32.1)$ & & & & \\
\hline \multicolumn{2}{|c|}{ Body mass index $\left(\mathrm{kg} / \mathrm{m}^{2}\right)$} & 0.437 & & & \\
\hline$\geq 25$ & $82(29.3)$ & & & & \\
\hline$<25$ & $198(61.7)$ & & & & \\
\hline ly & & 0.137 & & & \\
\hline Negative & $86(41.0)$ & & & & \\
\hline Positive & $124(59.0)$ & & & & \\
\hline v & & 0.024 & 0.464 & $0.229-0.938$ & 0.033 \\
\hline Negative & $180(64.7)$ & & & & \\
\hline Positive & $98(35.3)$ & & & & \\
\hline \multicolumn{2}{|c|}{ Histology findings } & 0.335 & & & \\
\hline Well/mod & $256(91.4)$ & & & & \\
\hline Other & $24(8.6)$ & & & & \\
\hline$T$ factor & & 0.223 & & & \\
\hline $\mathrm{T} 1,2,3$ & $245(87.5)$ & & & & \\
\hline T4 & $35(12.5)$ & & & & \\
\hline \multicolumn{2}{|l|}{ Tumour location } & 0.631 & & & \\
\hline Right-side & $128(45.8)$ & & & & \\
\hline Left-side & $152(54.2)$ & & & & \\
\hline \multicolumn{2}{|c|}{ Tumour size $(\mathrm{cm})$} & 0.101 & & & \\
\hline$<5.00$ & $295(53.2)$ & & & & \\
\hline$\geq 5.00$ & $259(46.8)$ & & & & \\
\hline \multicolumn{2}{|c|}{ Emergency surgery } & 0.565 & & & \\
\hline No & $254(90.7)$ & & & & \\
\hline Yes & $26(9.3)$ & & & & \\
\hline \multicolumn{2}{|c|}{ Operation method } & 0.117 & & & \\
\hline Open & $97(34.6)$ & & & & \\
\hline Laparoscopic & $183(65.4)$ & & & & \\
\hline LMR & & 0.034 & 0.540 & $0.297-0.980$ & 0.043 \\
\hline$\geq 3.33$ & $165(58.6)$ & & & & \\
\hline$<3.33$ & $115(41.4)$ & & & & \\
\hline PLR & & 0.953 & & & \\
\hline$\geq 300$ & $57(20.3)$ & & & & \\
\hline$<300$ & $223(79.7)$ & & & & \\
\hline NLR & & 0.446 & & & \\
\hline$\geq 5.00$ & $48(17.1)$ & & & & \\
\hline$<5.00$ & $232(82.9)$ & & & & \\
\hline
\end{tabular}

This table shows the results of a comparison of long-term prognostic factors for Stage II cases based on the 
LMR classification.P $<0.05$ was considered to be statistically significant

Table 5. Results of long-term prognostic analysis based on LMR classification in Stage III cases 


\begin{tabular}{|c|c|c|c|c|c|}
\hline \multirow[b]{2}{*}{ Variable } & \multirow[b]{2}{*}{$N(\%)$} & \multirow{2}{*}{$\begin{array}{c}\text { Univariate analysis } \\
P \text {-value }\end{array}$} & \multicolumn{3}{|c|}{ Multivariate analysis } \\
\hline & & & Hazard ratio & $95 \% \mathrm{Cl}$ & $P$-value \\
\hline Sex & & 0.313 & & & \\
\hline Male & $154(56.4)$ & & & & \\
\hline Female & $119(43.6)$ & & & & \\
\hline Age (years) & & 0.002 & 1.973 & $0.979-3.978$ & 0.057 \\
\hline$<75$ & $191(70.0)$ & & & & \\
\hline$\geq 75$ & $82(30.0)$ & & & & \\
\hline Body mass inde & $x\left(\mathrm{~kg} / \mathrm{m}^{2}\right)$ & 0.648 & & & \\
\hline$\geq 25$ & $70(25.6)$ & & & & \\
\hline$<25$ & $203(74.4)$ & & & & \\
\hline ly & & 0.361 & & & \\
\hline Negative & $28(15.5)$ & & & & \\
\hline Positive & $153(84.5)$ & & & & \\
\hline v & & 0.128 & & & \\
\hline Negative & $187(69.1)$ & & & & \\
\hline Positive & $84(30.9)$ & & & & \\
\hline Histology findin & & 0.08 & & & \\
\hline Well/mod & $249(91.2)$ & & & & \\
\hline Other & $24(8.8)$ & & & & \\
\hline T factor & & 0.06 & & & \\
\hline $\mathrm{T} 1,2,3$ & $206(75.5)$ & & & & \\
\hline T4 & $67(24.5)$ & & & & \\
\hline $\mathbf{N}$ (number) & & 0.01 & 0.501 & $0.254-0.990$ & 0.047 \\
\hline $1 \sim 3(\mathrm{~N} 1)$ & $178(65.2)$ & & & & \\
\hline $4 \sim(\mathrm{N} 2 / \mathrm{N} 3)$ & $95(34.8)$ & & & & \\
\hline Tumour locatio & & 0.474 & & & \\
\hline Right-side & 115 (42.1) & & & & \\
\hline Left-side & $158(57.9)$ & & & & \\
\hline Tumour size (cr & & 0.13 & & & \\
\hline$<5.00$ & $141(51.6)$ & & & & \\
\hline$\geq 5.00$ & $132(48.4)$ & & & & \\
\hline Emergency surg & sery & 0.132 & & & \\
\hline No & $251(92.0)$ & & & & \\
\hline Yes & $22(8.0)$ & & & & \\
\hline Operation meth & & 0.117 & & & \\
\hline Open & $86(31.5)$ & & & & \\
\hline Laparoscopic & $187(68.5)$ & & & & \\
\hline LMR & & $<0.001$ & 0.383 & $0.160-0.915$ & 0.031 \\
\hline$\geq 2.68$ & 229 (83.9) & & & & \\
\hline$<2.68$ & $44(16.1)$ & & & & \\
\hline PLR & & 0.094 & & & \\
\hline$\geq 300$ & $42(15.4)$ & & & & \\
\hline$<300$ & 231 (84.6) & & & & \\
\hline NLR & & 0.015 & 1.101 & $0.426-2.845$ & 0.846 \\
\hline$\geq 5.00$ & 240 (87.9) & & & & \\
\hline$<5.00$ & $33(12.1)$ & & & & \\
\hline
\end{tabular}

This table shows the results of a comparison of long-term prognostic factors for Stage III cases based on the LMR classification. $\mathrm{P}<0.05$ was considered to be statistically significan 
Figures
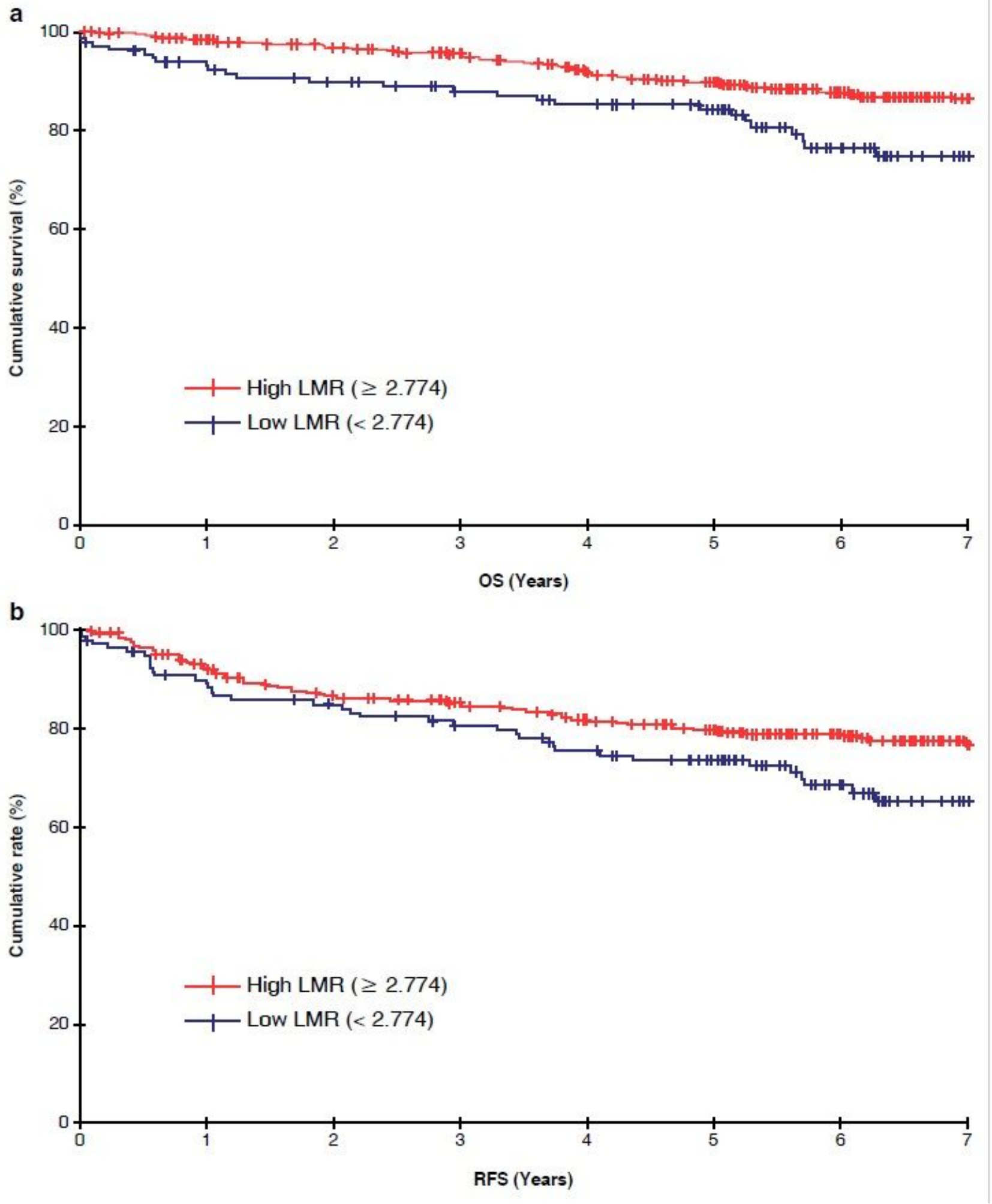

\section{Figure 1}

Overall survival (A) and recurrence-free survival (B) among colorectal cancer patients according to the lymphocyte-to-monocyte ratio. Survival curves were derived using the Kaplan-Meier method. $\mathrm{P}<0.05$ was considered to indicate statistical significance. 

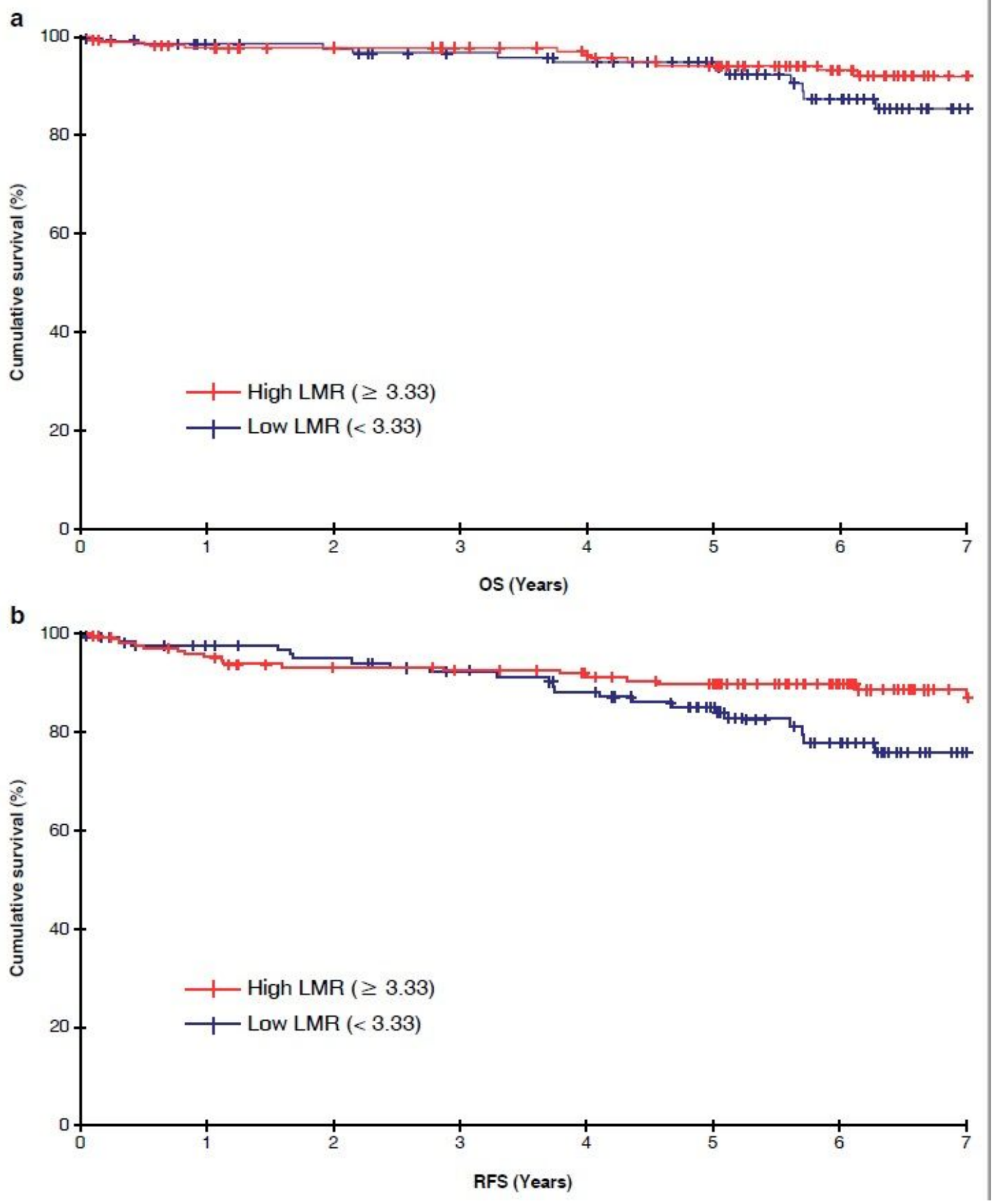

\section{Figure 2}

Overall survival (A) and recurrence-free survival (B) findings among colorectal cancer patients with Stage II disease according to the lymphocyte-to-monocyte ratio. Survival curves were derived using the KaplanMeier method. $\mathrm{P}<0.05$ was considered to indicate statistical significance. 
a
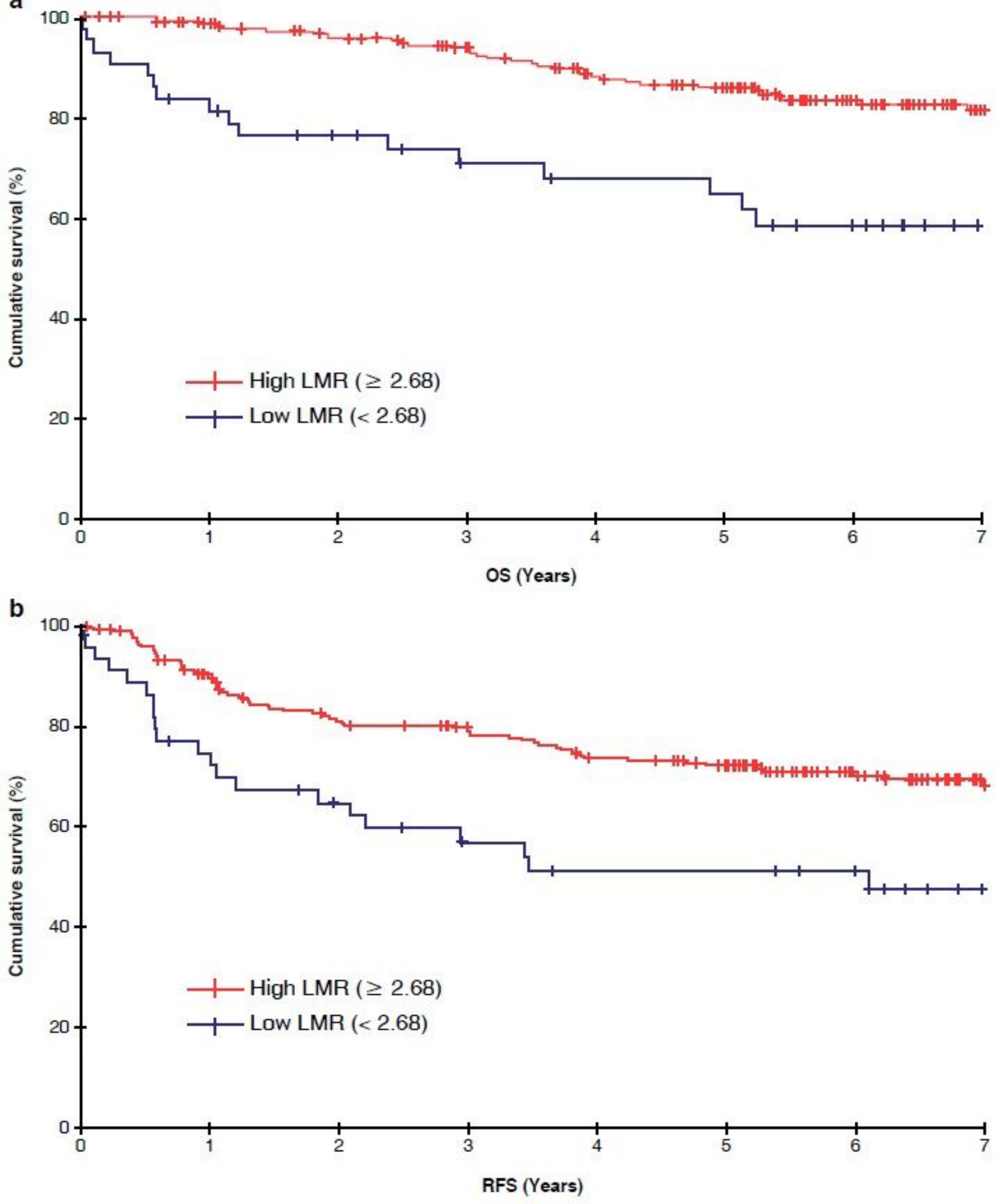

\section{Figure 3}

Overall survival (A) and recurrence-free survival (B) among colorectal cancer patients with Stage III disease according to the lymphocyte-to-monocyte ratio. Survival curves were derived using the KaplanMeier method. $\mathrm{P}<0.05$ was considered to indicate statistical significance. 